\title{
Muscle Cramp
}

National Cancer Institute

\section{Source}

National Cancer Institute. Muscle Cramp. NCI Thesaurus. Code C34827.

A sustained, sudden and involuntary contraction of a muscle or group of muscles. 